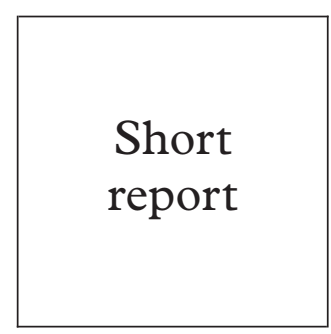

\author{
Nigel Dickson, Charlotte Paul, Peter Herbison
}

\title{
Where young people with multiple sexual partners seek medical care: implications for screening for chlamydial infection
}

Objective: To investigate among young people the relation between the number of sexual partners and use of medical services in order to guide planning of sexually transmitted disease screening.

Design: Cross sectional study within a birth cohort using a questionnaire presented by computer.

Setting: Dunedin, New Zealand in 1993-4.

Subjects: 477 men and 458 women aged 21 enrolled in the Dunedin Multidisciplinary Health and Development Study, comprising $91.7 \%$ of survivors of the cohort.

Results: Men with multiple sexual partners in the previous year were less likely to have a general practitioner than men with one or no partners $(76.2 \% v 88.5 \%, \mathrm{p}<0.01)$. Among the women the respective proportions $(83.1 \%$ and $88.4 \%)$ were not significantly different. Significantly more women than men $(75.8 \%$ v $50.7 \%, \mathrm{p}=0.03)$ with five or more partners in the previous year had visited their own general practitioner over that period. Among the sexually experienced, more women than men attended any setting appropriate for sexually transmitted disease screening $(93.6 \%$ v $71.6 \%, \mathrm{p}<0.001)$.

Conclusions: In New Zealand a screening programme for sexually transmitted diseases among young adults reliant on invitation by their own general practitioner would be biased towards those at less risk. Opportunistic screening in general practice would potentially include only about half the most sexually active men and three quarters of such women over a 12 month period. The extension of opportunistic screening to other settings considered appropriate for discussion of sexual health issues could potentially engage the vast majority of women, but not men, at most risk. Any screening programme should incorporate an effective method of finding and treating the sexual partners of infected women.

(Sex Transm Inf 1998;74:445-447)

Keywords: sexual behaviour; health service use; screening; chlamydial infection; New Zealand

\section{Introduction}

Interest in screening for genital chlamydial infection has increased with the appreciation that it can lead to a reduction in the incidence of pelvic inflammatory disease among sexually active women. ${ }^{1-3}$ The recent development of sensitive simple screening tests has made such screening a more practical proposition. ${ }^{2}$ An added incentive is that screening has been determined to be cost effective in populations with a prevalence of $6 \%$ or more. ${ }^{4}$

In New Zealand, as in England and Wales, although incidence is not known, among sexual health clinic attenders chlamydial infection is most commonly diagnosed among men age 20-24, and women age $15-19 . .^{56}$ For an individual the risk of sexually transmitted disease is strongly related to the number to sexual partners, with young age an additional factor. ${ }^{7}$ Within a population, people with a high rate of partner change are a core group with respect to the maintenance of sexually transmitted diseases. ${ }^{8}$ Mathematical modelling has shown that the effectiveness of screening in reducing the prevalence of chlamydial infection is greatly increased through targeting of individuals who comprise the core group. ${ }^{9}$

A key consideration in the development of programmes for screening for chlamydial infection is ascertaining which health services are used by those young adults most at risk of sexually transmitted disease, and hence where it would be appropriate to offer sexually transmitted disease screening. Screening could then be offered either by invitation, for those with a regular doctor, or opportunistically for attenders at any appropriate service. We have investigated this by combining data collected on sexual behaviour and health service use in a study of young New Zealand adults.

\section{Methods and sample}

The sample was enrolled in the Dunedin Multidisciplinary Health and Development Study, a longitudinal study of a cohort born in Dunedin, New Zealand between 1 April 1972 and 31 March 1973. The full history of the sample has been described by Silva and Stanton. ${ }^{10}$

Part of the assessment at age 21 included collection of information on the use of health services (for any reason) in the previous 12 months, and on sexual activity, including the number of sexual partners in the previous year. Wherever possible the sample members returned to Dunedin for the assessment even if living elsewhere in New Zealand or overseas. 
Table 1 Number (\%) reporting having their own doctor/general practitioner, attending their own doctor/general practice in past 12 months, and attending a doctor at any setting appropriate for screening for sexually transmitted diseases, by number of partners in past 12 months

\begin{tabular}{|c|c|c|c|c|c|}
\hline & \multirow[b]{2}{*}{ Never had sex } & \multicolumn{3}{|c|}{$\begin{array}{l}\text { No of sexual partners in previous } 12 \text { months } \\
\text { among sexually experienced }\end{array}$} & \multirow{2}{*}{$\begin{array}{l}\chi^{2} \text { for trend } \\
\text { among sexually } \\
\text { experienced }\end{array}$} \\
\hline & & None or 1 & $2-4$ & 5 or more & \\
\hline $\operatorname{Men}(n=471)$ & $\mathrm{n}=56$ & $\mathrm{n}=188$ & $\mathrm{n}=160$ & $\mathrm{n}=67$ & \\
\hline Have own general practitioner & $48(85.7 \%)$ & $168(89.4 \%)$ & $124(77.5 \%)$ & $49(73.1 \%)$ & $\mathrm{p}<0.001$ \\
\hline Attended own general practitioner & $24(42.9 \%)$ & $107(56.9 \%)$ & $87(54.3 \%)$ & $34(50.7 \%)$ & $\mathrm{p}=0.38$ \\
\hline Attended doctor at any setting appropriate for screening & $34(60.7 \%)$ & $140(74.5 \%)$ & $114(71.3 \%)$ & $43(64.2 \%)$ & $\mathrm{p}=0.34$ \\
\hline Women $(n=458)$ & $\mathrm{n}=37$ & $\mathrm{n}=267$ & $\mathrm{n}=121$ & $\mathrm{n}=33$ & \\
\hline Have own general practitioner & $35(94.6 \%)$ & $234(87.6 \%)$ & $103(85.1 \%)$ & $25(75.8 \%)$ & $\mathrm{p}=0.085$ \\
\hline Attended own general practitioner & $26(70.3 \%)$ & $203(76.0 \%)$ & $89(73.6 \%)$ & $25(75.8 \%)$ & $\mathrm{p}=0.75$ \\
\hline Attended doctor at any setting appropriate for screening & $29(78.4 \%)$ & $246(92.1 \%)$ & $116(95.9 \%)$ & $32(97.0 \%)$ & $\mathrm{p}=0.12$ \\
\hline
\end{tabular}

The questions were presented and the answers collected by computer.

Of the 1037 members of the cohort formed at aged 3 years, 1020 were believed to be alive at the 21 year old assessment in 1993 and 1994, and 935 (91.7\%), 477 men and 458 women, completed the questions on sexual behaviour. Overall, $90.0 \%$ of those interviewed reported having had sexual intercourse by age 21 . The cumulative incidence of self reported sexually transmitted diseases were $7.5 \%$ and $15.9 \%$ for the men and women respectively, and the risk increased steeply with the number of sexual partners for both sexes. ${ }^{11}$

Of the 477 men, 471 also answered the questions on use of health services, as did all 458 of the women. These questions included whether they had their own doctor/general practitioner, and whether they had seen any doctor in the past year. Those who reported seeing a doctor were asked specifically about the types of health service where this had occurred. For this analysis, settings considered potentially appropriate for chlamydia screening were general practice, student health, family planning or sexual health clinics. Settings considered inappropriate were hospital or private specialist clinics (details of the type of specialist clinic were not collected), accident and emergency departments, sports medicine clinics, and all other types.

Rates were compared using $\chi^{2}$ and $\chi^{2}$ for trend tests, using the statistical package EPI-INFO. ${ }^{12}$

\section{Results}

The key findings are presented in table 1 . The men with multiple partners in the past 12 months were less likely to have a general practitioner than those who had one or no partner $(76.2 \%$ v $88.5 \%, \mathrm{p}<0.001)$. Among the women the respective proportions $(83.1 \%$ and $88.4 \%)$ were not significantly different. For the sexually experienced men, the more sexual partners in the previous year, the less likely they were to have their own general practitioner. The trend was not significant for women.

Significantly more women than men $(75.8 \%$ $v 50.7 \%, \mathrm{p}=0.03$ ) with five or more partners in the previous year had visited their own general practitioner over that period. There was no significant trend for such attendance by number of sexual partners.

Among the sexually experienced, more women than men attended any setting appropriate for sexually transmitted disease screen- ing $(93.6 \% v 71.6 \%, \mathrm{p}<0.001)$. Although there was no statistically significant trend in such attendance with number of sexual partners for either sex, different patterns of attendance at such a setting were found for men and women. Among the men, fewer of those who had multiple partners reported attending an appropriate setting; however, the reverse was found for the women.

\section{Discussion}

This is one of the few studies that provides insight into how health service use overall varies with sexually transmitted disease risk. The findings of this analysis have implications for planning a screening programme for chlamydial infection (or any other sexually transmitted disease) for a population. In New Zealand the provision of sexual health services is similar to Britain. There is free access to hospital based sexual health clinics in the main urban areas; however, a significant proportion of people with sexually transmitted diseases are managed at other sites, in particular general practice or family planning clinics. ${ }^{11}$

The results suggest that in New Zealand a screening programme for sexually transmitted diseases among young adults, reliant on invitation by their own general practitioner, would be biased towards those at less risk, and fail to even potentially enrol around one quarter of both sexes most at risk. For the men, opportunistic screening when attending their own general practitioner would fare even worse as only half attend their general practitioner in a year. Extending opportunistic screening to other settings considered appropriate for discussion of sexual health issues could possibly improve coverage for men at more risk, but not over recall in general practice. However, such extension would be more likely to engage women at higher risk, and could potentially engage the vast majority of women at most risk. These findings suggest that it would be easier to make available to young women than men a programme of screening for sexually transmitted disease.

In view of a relatively high proportion of high risk men who have no general practitioner or contact with medical care, an effective screening programme should incorporate a strategy for finding and treating the sexual partners of infected people, especially for male partners of infected women. However, as general practitioners may have had little training or experience in this area, they should develop a close 
working relationship with those in the public health and sexual health services who can provide support when needed.

Our findings are compatible with the advice in a recent report by the Chief Medical Officer's Expert Advisory Group on Chlamydia trachomatis in Britain. ${ }^{13}$ It recommends that opportunistic screening of sexually active women aged under 25 should be introduced in a number of settings where information on age and sexual activity could be sought, such as general practice and family planning clinics. It also recommends that people found to be infected there should be referred to genitourinary medicine clinics for further management, particularly because of the expertise of these clinics in partner notification procedures. The expert group argued for a concentration on women because the sequelae are more serious for women, that women were more likely to attend a healthcare setting where screening is feasible, and that computer modelling suggests it is cost effective.

Our study gives further support for targeting young women and using opportunistic screening not only in general practice but also in other primary care settings such as family planning, student health, and sexual health clinics.

This study was part of the Dunedin Multidisciplinary Health and Development Study, directed by Dr Phil Silva and funded by the Health Research Council of New Zealand. We thank the sample members and their families for their long term involvement in the study.

1 Stokes T. Screening for chlamydia in general practice: a literature review and summary of the evidence. $\mathcal{F}$ Pub Health Med 1997;19:222-32.

2 Mårdh P-A. Is Europe ready for STD screening. Genitourin Med 1997;73:96-8.

3 Scholes D, Stergachis A, Heidrich FE, et al. Prevention of pelvic inflammatory disease by screening for cervical chlamydia infection. N Engl F Med 1996:334:1362-6.

4 Genc M, Ruusuvaara L, Mårdh P-A. An economic evaluation of screening for Chlamydia trachomatis infection in adolescent males. FAMA 1993;17:2057-64.

5 Epidemiology Group, ESR. STD surveillance data. Wellington, New Zealand: ESR, 1998.

6 Connor N, Catchpole M, Rogers PA, et al. Sexually transmitted diseases among teenagers in England and Wales. Commun Dis Rep CDR Review 1997;7:R173-8.

7 Laumann EO, Gagnon JH, Michael RT, et al. The social organisation of sexuality. Chicago: University of Chicago Press, 1994.

8 Brunham RC, Plummer FA. A general model of sexually transmitted disease epidemiology and its implications for control. Med Clin N Am 1990;74:1339-52.

9 Kretzschmar M, van Duynhoven YTHP, Severijnen AJ. Modeling prevention strategies for gonorrhea and chlamydia using stochastic network simulations. Am 7 Epidemiol 1996;144:306-17.

10 Silva PA, Stanton WR, eds. From child to adult: the Dunedin multidisciplinary health and development study. Auckland: Oxford University Press, 1996

11 Dickson NP, Paul C, Herbison P, et al. The lifetime occurrence of sexually transmitted diseases among a cohort aged 21. NZ Med f 1996;109:308-12.

12 Dean A, Dean J, Burton A, et al. EpiInfo Version 5. Stone Mountain, Georgia: USD Inc, 1990.

13 Department of Heath. Summary and conclusion of CMO's Expert Advisory Group on Chlamydia trachomatis. London: DoH, 1998. 